\title{
Mito, olvido y manipulación de la historia de la masonería
}

\section{Myth, Forgetfulness and Manipulation of the History of Freemasonry}

\author{
José Antonio Ferrer Benimeli \\ Universidad de Zaragoza, España \\ bibliotecasalvadorzaragoza@gmail.com
}

Recepción: 8 de marzo de 2019/Aceptación: 14 de abril de 2019.

doi: https://doi.org/10.15517/rehmlac.v11i1.36976

Palabras clave

Mito; olvido; manipulación; masonería; historiografía.

Keywords

Myth; Forgetfulness; Manipulation; Freemasonry; Historiography.

\section{Resumen}

Con ocasión del XV Symposium Internacional de Historia de la Masonería española celebrado en Lisboa, en octubre de 2018, en torno a Mitos e Historia, de los 10 años de la revista REHMLAC+ se viene reflexionando a modo de balance sobre las investigaciones realizadas en estos últimos 40 años por parte de la historiografía y su alcance en el conocimiento real del fenómeno masónico. Aprovechando la reunión del Seminario Permanente Internacional de Historia de las Masonerías en Gijón, en febrero de 2019, se presenta una síntesis alrededor del mito, olvido y manipulación de la Historia de la Masonería con el deseo que algún día la realidad del pasado masónico ocupe el lugar que se apropiaron sus mitos y leyendas.

\section{Abstract}

On the occasion of the XV International Symposium on the History of Spanish Masonry held in Lisbon, in October 2018, entitled Myth and History, as well as, the $10^{\text {th }}$ Anniversary of the journal REHMLAC+ there was an assesment of the historiographical research conducted in the last 40 years and its scope in the real knowledge of the Masonic phenomenon. In light of the meeting of the International Seminar on the History of Masonry that took place in Gijón, in February 2019, this article presents a synthesis around the myth, the forgoten, and the manipulation of the history of Freemasonry with the objective that one day the true Masonic past will occupy the place that myths and legends about the history of Freemasonery had occupied and approproated until now.

Estamos conmemorando los diez primeros años de la Revista de Estudios Históricos de la Masonería Latinoamericana y Caribeña [REHMLAC] por lo que en las reflexiones que en voz alta vamos a compartir quisiera empezar añadiendo un pequeño matiz y complemento al título de mi intervención: Mito, olvido y manipulación de la historia de la masonería latina, es decir la ibero, hispana o sudamericana, según las preferencias de cada uno. Y lo voy a hacer recordando al profesor canario-sevillano Francisco Morales Padrón quien en su Historia de América observaba hace ya 36 años que todavía no había un libro de conjunto que estudiara el papel de la masonería en la independencia o en la historia de América. Hoy día seguimos careciendo de esa publicación si bien es cierto que se ha dado un gran paso en estos últimos años, pues, desde algunas universidades americanas y europeas, así como desde el CEHME, el Grupo La Habana y la revista REHMLAC se han ido publicando muchos y valiosos estudios sobre la masonería en la llamada América Latina, desde el cono sur (Chile y Argentina) hasta 
México y el Caribe. Universidades y Centros de estudio donde la masonería ha alcanzado el estatus de objeto histórico ${ }^{1}$.

Sin embargo, como se puso de manifiesto en el XV Symposium Internacional de Historia de la Masonería Española (Lisboa, 2018), centrado en torno a los mitos y equívocos de la historiografía masónica, siguen siendo muchos los tópicos y leyendas que rodean la historia de la masonería, en especial la hispana o latinoamericana y en particular los referidos a los protagonistas de la emancipación o independencia.

Marco Aurelio Skinner Vásquez ${ }^{2}$ en su ensayo sobre el posible influjo de la masonería en la revolución independentista de la Gran Colombia, donde se pregunta si dicho influjo es verdad o mito, reconoce que en el inconsciente colectivo de los hispanoamericanos existe un mítico recuerdo que dice: la masonería influyó notablemente en la libertad de estas naciones, pero no es fácil encontrar pruebas de esta afirmación.

Como contrapartida en la mayor parte de la historiografía universitaria americana y europea la masonería ni siquiera es mencionada al tratar de la independencia y de los llamados libertadores.

El colombiano Gilberto Loaiza Cano, de las universidades Nacional de Colombia y del Valle en Cali, afirma que "ni siquiera los estudios biográficos sobre los dirigentes políticos del siglo XIX en Colombia han contemplado en sus análisis las relaciones de sus biografiados con la militancia masónica"3. En la mayor parte de los casos los biógrafos han preferido omitir cualquier vinculación con la masonería de sus biografiados ${ }^{4}$.

Y para el caso de Colombia las omisiones más llamativas son las de Francisco de Paula Santander y Tomás Cipriano de Mosquera promotores y líderes indiscutibles de la masonería colombiana y de la primera implantación de redes de logias.

Sin embargo, este vacío de la historiografía universitaria americana y europea hasta fechas relativamente recientes fue ocupado por aportaciones más o menos valiosas de militantes masones como Américo Carnicelli, Julio Hoenisberg y el más reciente de Mario Arango

\footnotetext{
${ }^{1}$ Esta falta de interés historiográfico por la masonería, denunciado en su día por Francisco Morales Padrón, Historia de América (Madrid: Espasa Calpe, 1962), 100, más recientemente lo fue también -entre otros- por Pilar González-Bernaldo de Quirós, Civilité et politique aux origines de la nation argentine. Les sociabilités à Buenos Aires, 1829-1862 (Paris: Publications de la Sorbonne, 1999) (versión en español en Fondo de Cultura Económica, 2002); Jean-Pierre Bastian, "Una ausencia notoria: la francmasonería en la historiografía mexicanista", Historia Mexicana 3 (1995), 439-460; Mario Arango Jaramillo, Masonería y poder político en Colombia (Medellín: Hombre Nuevo Ed., 2011); Gilberto Loaiza Cano, "La masonería y las facciones del liberalismo colombiano durante el siglo XIX. El caso de la masonería de la Costa Atlántica", Historia y Sociedad 13 (2007): 65-89, http://bdigital.unal.edu.co/23504/1/20438-68977-1-PB.pdf

${ }^{2}$ Marco Aurelio Skinner Vásquez, Influencia de la masonería en la revolución independentista de la Gran Colombia. ¿Verdad o mito? (Bucaramanga: 2013).

${ }^{3}$ Loaiza Cano, "La masonería y las facciones", 3.

${ }^{4}$ Como excepción Loaiza cita los estudios sobre Antonio Nariño y Manuel Ancízar. Enrique Santos Molano, Antonio Nariño, filósofo y revolucionario (Bogotá: Planeta, 1999); Loaiza Cano, Manuel Ancízar y su época (Medellín: Universidad Nacional de Colombia, 2004).
} 
Jaramillo ${ }^{5}$ o de antimasones mucho más numerosos y en general más desafortunados como el prolífico José Patricio Maguirre o Ramón Martínez Zaldúa ${ }^{6}$.

Un caso especial por el gran número de publicaciones que se han ocupado de ellas, aunque no siempre con el acierto y objetividad históricos deseables, lo constituyen algunas logias o pseudologias, especialmente las llamadas Lautaro ${ }^{7}$ que, como es bien sabido, no eran logias masónicas sino político-patrióticas y que pertenecen a un momento muy concreto de la historia de América, especialmente vinculado con la independencia, emancipación o revolución de principios del siglo $\mathrm{XIX}^{8}$. Corresponden al estudio, con frecuencia confuso, del papel desempeñado no solo por la masonería sino por las sociedades secretas en general, sean estas masónicas, políticas, patrióticas, militares, literarias, económicas o filológicas, como la que atentó contra Bolívar en $1828^{9}$.

Estos últimos cuarenta años la masonería ha sido estudiada en el contexto de esas prácticas asociativas y de construcción de los nuevos estados-naciones americanos. La historia de la masonería de principios del siglo XIX es presentada como una forma más de cultura política o de sociabilidad cosmopolita basada en la armonía y tolerancia política, social, religiosa y en la fraternidad.

Es el caso de Eduardo Torres Cuevas para Cuba y de Francisco Javier Guerra, María Eugenia Vázquez Semadeni, Carlos Francisco Martínez Moreno, Guillermo de los Reyes y Marco Antonio Flores Zavala para México ${ }^{10}$, de Pilar González Bernaldo de Quirós para Argentina $^{11}$, de Felipe Santiago del Solar para Chile ${ }^{12}$, o de Gilberto Loaiza Cano para Colombia y de Miguel Guzmán-Stein y Ricardo Martínez Esquivel para Costa Rica ${ }^{13}$.

\footnotetext{
${ }^{5}$ Julio Hoenigsberg, Influencia revolucionaria de la masonería en Europa y América (Bogotá: 1944); Américo Carnicelli, La masonería en la independencia de América (Bogotá: 1970), 2 vols. y Historia de la masonería colombiana, 1833-1940 (Bogotá: 1975), 2 vols.; Arango Jaramillo, Masonería y partido liberal. Otra cara en la historia de Colombia (Medellín: Corselva, 2006).

${ }^{6}$ José Patricio Maguirre, "Algunos antecedentes para evaluar la influencia de la masonería en la liberación de Hispanoamérica”, Boletín del Instituto de Historia Argentina, no. 16-11 (1968-1969); Ramón Martínez Zaldúa, La masonería en Hispanoamérica (Su influencia decisiva en la revolución mexicana) (México: B. Costa-Amie, 1965).

${ }^{7}$ Nombre adoptado del guerrero mapuche y caudillo araucano que venció al conquistador Valdivia en 1554 . Alonso de Ercilla y Zúñiga, La Araucana (Madrid: Gaspar y Roig Ed. 1852).

${ }^{8}$ José Antonio Ferrer Benimeli, "Las logias Lautaro, los caballeros racionales y el movimiento independentista americano", en Masonería y sociedades secretas en México, coord. por José Luis Soberanes Fernández y Carlos Francisco Martínez Moreno (México: UNAM, 2018), 41-70.

${ }^{9}$ Ferrer Benimeli, "Bolívar y la masonería”, Revista de Indias 172 (julio-diciembre 1983): 631-687.

${ }^{10}$ Eduardo Torres Cuevas, Historia de la masonería cubana. Seis ensayos (La Habana: Imagen Contemporánea, 2004); François-Xavier Guerra, Le Mexique, de l'Ancien régime à la Révolution, (Paris, Publications de la Sorbonne, 1985); María Eugenia Vázquez Semadeni, La formación de una cultura política republicana. El debate público sobre la masonería. México, 1821-1830 (México: UNAM, 2010); Carlos Francisco Martínez Moreno, "El establecimiento de las masonerías en México en el siglo XIX" (Tesis de Maestría, UNAM, 2011); Guillermo de los Reyes Heredia, Herencias secretas. Masonería, política y sociedad en México. El impacto de la masonería en el discurso nacionalista, secular y liberal en México (Puebla: Universidad Autónoma, 2009); Marco Antonio Flores Zavala, “Masonería y masones en México, 1760-1936” (Tesis doctoral, Universitat Jaume I, 2016).

11 González-Bernaldo de Quirós, Civilité et politique.

${ }^{12}$ Felipe Santiago del Solar, Las logias de ultramar. En torno a los orígenes de la francmasonería en Chile 18501862 (Santiago de Chile: Occidente, 2012).

${ }^{13}$ Loaiza Cano en nota 1. Miguel Guzmán-Stein, "Liberalismo, Educación, Iglesia y Masonería: el proceso de formación y secularización del estado nacional a través de las relaciones institucionales en Costa Rica en el siglo XIX” (Tesis doctoral, universidad de Zaragoza, 2005); Ricardo Martínez Esquivel, Masones y masonería en la
} 
Y si bien es cierto que en la segunda mitad del siglo XIX gran parte de la clase política de Argentina, México y Colombia -por poner solo tres ejemplos representativos por supuesto extensibles al resto de países del área geográfica ibero americano- militó en las logias, sin embargo, en el primer tercio de siglo la práctica asociativa masónica estuvo mucho más diluida en las élites político-intelectuales. En primer lugar, porque la introducción de la masonería en esos países es bastante posterior a la independencia, lo que lleva a preguntarnos si la masonería en Hispanoamérica es causa o más bien consecuencia de la independencia; y en segundo lugar porque no es lo mismo que se localice alguna logia o pseudologia implantada desde el extranjero a que exista una masonería autóctona organizada e institucionalizada como tal.

El origen de la famosa y controvertida "logia" Lautaro de Buenos Aires se suele situar en 1812. Sin embargo, la masonería argentina se constituye en 1857, como recordaba en 1982 el Gran Maestre Carlos Wilson con motivo de la celebración del 125 aniversario de la Gran Logia de Argentina de Libres y Aceptados Masones ${ }^{14}$. Otro tanto podríamos decir de Chile que conmemoró en 2012 los 150 años de la fundación de la Gran Logia de Chile en mayo de 1862, como puso de manifiesto el Gran Maestre Luis A. Riveros en su discurso conmemorativo. Y más recientemente, en octubre 2018 la Gran Logia de la República Dominicana celebraba los 180 años de su fundación en 1868.

Muy vinculado con lo anterior está el protagonismo desempeñado por los llamados libertadores y su presunta o real pertenencia a la masonería, aunque en realidad del único del que hay constancia documental fidedigna de que fue iniciado en una logia masónica y por tanto fue masón, al menos en un período breve de su vida es el de Simón Bolívar, lo que no ocurre, por ejemplo, con Miranda, San Martín, O’Higgins y tantos otros convertidos en héroes nacionales y símbolos de la patria aunque su filiación no siempre resulte clara o tan suficientemente probada como la de Bolívar.

Sin embargo, Bolívar, que recibió los tres primeros grados de la masonería en 1805 en la logia San Alejandro de Escocia, de París, ya no volvió a militar en ninguna otra logia masónica europea o americana ${ }^{15}$. Dicho con otras palabras, que frente a unos meses o semanas de militancia masónica en París estamos ante 25 ó 26 años posteriores de alejamiento masónico, o al menos de ausencia de noticias de una participación directa.

Más aún, a raíz del fracaso de la Convención de Ocaña en junio de 1828, que enfrentó a los partidarios del general Santander y los de Bolívar, y del también fracaso de la conspiración contra Bolívar y su intento de asesinato por la Sociedad Filológica, a finales de septiembre del mismo año ${ }^{16}$, Bolívar y sus ministros estimaron conveniente prevenir futuras conspiraciones,

Costa Rica de los albores de la Modernidad (1865-1899) (San José: Editorial de la Universidad de Costa Rica, 2017).

${ }^{14}$ Carlos Wilson, “125 años de Masonería”, La palabra de la Masonería 1 (diciembre 1982): 5-8.

${ }^{15}$ Carnicelli, La masonería en la independencia de América, vol. II, 374-376, cuando proporciona la Lista de masones de 1809 a 1828 no puede menos de señalar a Simón Bolívar, Libertador, como miembro de la logia San Alejandro de Escocia, de Paris, siendo el único que no aparece en logia americana, lo que supone un reconocimiento indirecto de su no actividad masónica en la tierra que él liberó o independizó.

${ }^{16}$ Sorprendieron la guardia que custodiaba la casa residencia del Libertador Presidente General Simón Bolívar, quien se salvó de ser asesinado por el valor de doña Manuela Sáenz que le animó a lanzarse a la calle desde un balcón, mientras ella entretenía a los conspiradores, con lo que pudo escapar. Doña Manuela, llamada la Libertadora del Libertador fue su amante desde el 15 de junio de 1822, día en que se conocieron en Quito en el baile que don Juan Larrea dio en honor de Bolívar, quien acababa de llegar de Pasto. El idilio duró hasta la muerte del Libertador, ocurrida en San Pedro Alejandrino, Santa Marta, el 17 de diciembre de 1830. 
evitando reuniones ilegales, bajo pretexto de sociedades culturales, y al efecto expidió el decreto de 8 de noviembre de 1828, sobre la prohibición en el territorio de la república de Colombia "de las asociaciones o confraternidades secretas". Ciertamente en el decreto no se menciona concretamente la masonería, pero tácitamente quedó incluida. Desde el día 8 de noviembre de 1828 se disolvía oficialmente la masonería en Colombia.

Sobre la actitud personal de Bolívar y el porqué de su ingreso en la masonería son reveladoras las palabras que el francés Luis Perú de Lacroix, mariscal de campo de Bolívar y coronel del Ejército de la Gran Colombia, recoge en el célebre Diario de Bucaramanga donde glosa así unas confidencias que -según él- le hizo el libertador el domingo 11 de mayo de 1828, siete meses antes del decreto de prohibición:

Habló sobre la Masonería, diciendo que también había tenido él la curiosidad de hacerse iniciar para ver de cerca lo que eran aquellos misterios, y que en París había sido recibido Maestro, pero que aquel grado le había bastado para juzgar lo ridículo de aquella antigua asociación; en las Logias había hallado algunos hombres de mérito, bastantes fanáticos, muchos embusteros y muchos más tontos burlados; que todos los masones parecen a (sic) unos grandes niños, jugando con señas, morisquetas, palabras hebraicas, cintas y cordones; que sin embargo la política y los intrigantes pueden sacar algún partido de aquella sociedad secreta, pero que en el estado de civilización de Colombia, de fanatismo y de preocupaciones religiosas en que están sus pueblos, no era político valerse de la Masonería, porque para hacerse algunos partidarios en las Logias se hubiera atraído el odio y la censura de toda la Nación, movida entonces contra él por el clero y los frailes, que se hubieran valido de aquel pretexto; que por lo mismo poco podía hacerle ganar la Masonería, y hacerle perder mucho en la opinión ${ }^{17}$.

Este texto sintetiza bien la posición de Bolívar hacia la masonería, a juicio de Nicolás E. Navarro, editor del Diario de Bucaramanga, quien no duda de que el oficial francés recogió fielmente el pensamiento del Libertador, pues Perú de Lacroix era él mismo masón, grado 33, y no tenía ningún interés en ridiculizar o subestimar la institución a la cual pertenecía ${ }^{18}$.

Volviendo al decreto de prohibición resulta curiosa la fundamentación ideológica que el mismo Bolívar hace en él. Dice así:

\section{SIMÓN BOLÍVAR}

Libertador Presidente de la República de Colombia...

Habiendo acreditado la experiencia tanto en Colombia como en otras naciones, que las sociedades secretas sirven para preparar los trastornos políticos, turbando la tranquilidad pública, y el orden establecido; que ocultando tras ellas todas sus operaciones con el velo del misterio, haciendo presumir fundamentalmente que no son buenas ni útiles a la sociedad, y por lo mismo excitan sospechas y alarmas a todos aquellos que ignoran los objetos de que se ocupan, oído el dictamen del Consejo de Ministros,

DECRETA:

Artículo $1 .^{\circ}$ Se prohíben en Colombia todas las asociaciones o confraternidades secretas, sea cual fuere la denominación de cada una...

\footnotetext{
${ }^{17}$ Luis Perú de Lacroix, Diario de Bucaramanga (Caracas: Edición de Monseñor Nicolás E. Navarro, 1935).

${ }^{18}$ Nicolás Eugenio Navarro, Tópicos bolivarianos. Glosas al "Diario de Bucaramanga” (Caracas: 1933): 17-20.
} 
Aquí la fórmula utilizada en el decreto de Bolívar por la que se prohibían "todas asociaciones o confraternidades secretas, sea cual fuere la denominación de cada una" recuerda otro decreto anterior, del año 1817, del arzobispo de Granada en el que se incluye la bula de León XII prohibiendo y condenando de nuevo "toda secta o sociedad clandestina, cualquiera que sea su denominación..." ${ }^{19}$.

En la década de 1820 las logias masónicas se introducen en la América hispana sobre todo vía Jamaica, Francia y Estados Unidos ${ }^{20}$, y se entremezclan o sustituyen a las sociedades patrióticas Lautaro.

Gilberto Loaiza Cano apunta que desde esas fechas la logia sirve para aglutinar a las facciones o partidos que se disputaban el control del proceso organizativo de las postindependencias. Y trae precisamente el ejemplo del complot contra Bolívar apoyado por un grupo de masones bajo la dirección de Francisco de Paula Santander, fundador en Bogotá de la logia Libertad de Colombia. En el otro extremo cronológico de la historia política del siglo XIX sitúa la aprobación de la constitución colombiana de 1886 cuando la masonería de ese país más vinculada al liberalismo radical fue de nuevo blanco de persecución y prohibiciones oficiales ${ }^{21}$.

Período este que resulta clave para entender la orientación ideológico-política de prácticamente toda la masonería latinoamericana tanto de Colombia, como de Perú, Argentina y el resto de las nuevas naciones constituidas en el triángulo formado entre el Pacífico, Atlántico y Caribe. Pues el papel que en la década de 1810 realizarán las sociedades patrióticas y "logias" Lautaro, en los años posteriores a las independencias lo llevarán a cabo algunas logias masónicas. Y la masonería en gran medida quedó identificada con el liberalismo radical ${ }^{22}$. Liberalismo que tendrá como compañeros de viaje al laicismo, y al anticlericalismo dentro de un proyecto más amplio político cultural cuya forma de expresión última será el republicanismo.

La república, principal objetivo de las sociedades patrióticas que lucharon por la independencia, plasmada en el juramento que tenían que realizar los miembros de las "Lautaro" "23, quedará recogida como forma de estado y gobierno en las Constituciones de los diferentes países que se independizaron de la monarquía española.

Juramento que recuerda el que también hizo Bolívar en el monte sacro de Roma como rechazo a la vía monárquico-imperialista adoptada por Napoleón Bonaparte tras su doble autocoronación, en 1805, como emperador en París y rey de los italianos en Milán.

\footnotetext{
${ }^{19}$ Sobre los decretos similares que por esos años dio Fernando VII en España contra las sociedades secretas, véase Ferrer Benimeli, Masonería española contemporánea (Madrid: Siglo XXI de España Ed., 1980), vol. 1, 152-160. ${ }^{20}$ Ferrer Benimeli, "Vías de penetración de la masonería en el Caribe", REHMLAC 1, no. 1 (mayo-noviembre 2009): 4-15, https://revistas.ucr.ac.cr/index.php/rehmlac/article/view/6853

${ }^{21}$ Loaiza Cano, "La masonería y las facciones", 2-3.

${ }^{22}$ En tanto que el liberalismo moderado o conciliador en algunos lugares se aproximará más a la Iglesia, a pesar de que para Roma la bestia negra será el liberalismo sin distinciones. Recordemos, entre otros muchos a Félix Sardá y Salvany, El liberalismo es pecado (Barcelona: Librería Católica, 1887); Masonismo y Catolicismo. Paralelos entre la doctrina de las logias y la de nuestra santa Iglesia católica apostólica y romana (Barcelona: Librería Católica, 1885).

${ }_{23}^{23}$ "No reconocerás por gobierno legítimo de tu patria sino a aquel que sea elegido por la libre y espontánea voluntad de los pueblos, y siendo el gobierno republicano el más adaptable a la libertad de América, propenderás por cuantos medios te sean posibles, a que los pueblos se decidan por esta clase de gobierno". Rómulo Avendaño, Revista de Buenos Aires, t. 19 (1869): 439. Navarro, La masonería y la independencia (Caracas: Ed. Sur-Americana, 1928), 29-30.
} 
Coronaciones en las que Bolívar estuvo presente debido a su primeriza admiración por Bonaparte pero que tras su radical desengaño provocado precisamente por sus autocoronaciones ["La corona que se puso Napoleón en la cabeza la miré como una cosa miserable y de estilo gótico" (Diario de Bucaramanga)] le reafirmaron en su vocación antimonárquica y republicana.

Las logias masónicas, en cierto modo herederas o mimetizadas con los ideales y fines de las sociedades patrióticas de la primera década del siglo XIX, también se identificaron con el ideal republicano. Y lo hicieron de una forma militante y proselitista a diferencia de algunas masonerías europeas establecidas en países entonces todavía monárquicos como Italia, España, Francia y Alemania, además de los ya tradicionales como Gran Bretaña, Bélgica, Holanda y los países escandinavos y bálticos, o incluso del propio Brasil cuyo emperador Pedro I era masón y fue el que llevó a cabo, en 1822, la independencia de esa colonia respecto de su metrópoli Portugal. En Brasil no sería proclamada la república federal hasta el año 1889.

Así pues, desde un punto de vista histórico, tanto de la historia americana como de la específicamente masónica, no tiene gran consistencia la identificación casi sagrada que, sobre todo en América, se hace entre masonería y república. Esta identificación hizo que la masonería del siglo XIX en Hispanoamérica se viera desde sus orígenes muy comprometida con los proyectos de laicización, en especial en la enseñanza, en nombre de un liberalismorepublicanismo con sus ambigüedades ideológicas, sobre todo en la historia político-religiosa de la segunda mitad del siglo XIX. Ambigüedades puestas de manifiesto en Colombia donde, según Carnicelli ${ }^{24}$ hubo dos corrientes masónicas radicalmente diferentes. Una de ellas en la costa atlántica, en torno al Supremo Consejo de Cartagena que se caracterizó porque los masones buscaron siempre conciliar los principios de la masonería con su fe católica. Mientras que la otra, que corresponde al centro y al oriente del país, fue más bien anticlerical, al estar vinculada al liberalismo radical. Entre los hechos más sintomáticos hay que señalar la presencia en el Supremo Consejo de Cartagena de 14 sacerdotes católicos, entre ellos dos obispos: Juan Fernández de Sotomayor y Calixto $\operatorname{Noguera}^{25}$ (el primero grado 33 y el $2^{\circ}$ grado 18) así como la del secretario del obispo de Santa Marta, Antonio González Carazo, seglar, miembro de la logia Unión Fraternal a la que informó debía ausentarse para acompañar al obispo Luis José Serrano durante su visita pastoral de la diócesis, en su calidad de secretario del mismo.

Estamos ante el reverso de la medalla de esa otra masonería liberal colombiana del interior basada en un ideal secularizador laico y en general antirreligioso y de control social del magisterio y actividades de la Iglesia católica.

Resulta llamativo constatar que este enfoque historiográfico en el que se pone el acento en la sociabilidad masónico-religiosa, o en el laicismo secularizador, así como en la cultura político-intelectual, dando especial protagonismo en el pasado de América a otros enfoques y militancias de iglesias ajenas y opuestas a la católica, es una línea de investigación a la que se ha prestado especial atención desde la facultad de teología protestante de la universidad Marc Bloch de Estrasburgo en figuras tan destacadas como la del pastor Pierre Bastian y sus

\footnotetext{
${ }^{24}$ Carnicelli, Historia de la masonería colombiana, vol. I, 39-91; vol. II, 37, 45, 98.

${ }^{25}$ Cuadro de sacerdotes masones del Supremo Consejo de Cartagena, elaborado con información de Carnicelli, por Loaiza Cano, "La masonería y las facciones", 17-18.
} 
discípulos Dévrig Molles y Gilberto Loaiza Cano ${ }^{26}$. Línea de investigación enriquecedora y complementaria de otras anteriores.

Una última reflexión en la línea de revisión de recientes trabajos realizados sobre la masonería iberoamericana en las primeras décadas del siglo XIX tanto en el sur (Colombia, Brasil, Argentina, Chile...) como en el centro (Cuba y Costa Rica) y en el norte (México). Se constata la necesidad de seguir analizando los años que preceden y siguen a la independencia que, como señala Ballester Escalas en su Simón Bolívar, "nació del grito 'mueran los franceses' y de las protestas de fidelidad al rey de España expulsado por el rey intruso José Bonaparte"27, pero también los de la segunda mitad del siglo XIX que tienen planteamientos y realidades muy distintas. En ambos períodos en el estudio de los grupos de poder destaca la importancia dada a la masonería en el debate público como una nueva forma de hacer política primero y de hacer historia después.

Aquí el protagonismo de la masonería radica en que es sujeto del debate público, no en una presencia o realidad masónica ya que en muchos casos ni siquiera existía dándose la paradoja de que se está hablando y polemizando sobre algo no existente y que se introduce mucho después. De ahí la ausencia de documentos y archivos, lo que dificulta la investigación histórica.

El debate público sobre la masonería va a dar origen y consistencia a un imaginario popular que se forma en torno a esta institución, con connotaciones positivas y negativas -más negativas que positivas- según las ideologías político-religiosas del lugar y del momento. Imaginario que se hace fuerte en el terreno de la polémica especialmente en la prensa y en la folletería tan rica y variada esta última en México. Pero la polémica pasará también al campo de la historia y la política.

La masonería real o ficticia acabará ocupando un espacio político en el momento en que en la América recién independizada se están buscando y construyendo identidades políticas. En el período 1826-1828 las logias masónicas o la masonería en general, identificada con otras sociedades más o menos secretas, se presenta como una nueva forma de hacer frente a los nacientes sistemas políticos. Eso hará que desde el parlamento chileno al mexicano, pasando por el decreto colombiano de Bolívar de 1828, la masonería, identificada como sociedad secreta política sea prohibida y perseguida en esos años en la mayor parte de las nuevas repúblicas hispanoamericanas.

De esta forma la masonería de ser protagonista pasa a ser proscrita y quedar al margen de la legalidad. La historia de la masonería en América en los años posteriores a la independencia, o la percepción histórica de la misma, se mueven, pues, en un terreno fronterizo entre el rechazo y la aceptación, entre el protagonismo político y la condena. En cualquier caso parece ser que tanto por unos como por otros se identifica, en el nuevo orden político institucional, con posturas en favor o en contra, como si resultara difícil -al igual que ocurre hoy día- mantenerse indiferente ante el hecho masónico.

\footnotetext{
${ }^{26}$ A los que habría que añadir para el caso europeo al neoconverso Luc Nefontaine.

${ }^{27}$ R. Ballester Escalas, Simón Bolívar (Barcelona: Ed. Toray, 1963), 45. Todavía en 1821 se seguía exigiendo a los habitantes de Nueva España la fidelidad al rey en el decreto que proclamaba la Independencia y la Unión, así como en el juramento establecido con arreglo al plan de D. Agustín de Iturbide, primer jefe del ejército de las tres garantías. Documentos Relativos a las últimas ocurrencias de Nueva España (Madrid: Ibarra, 1821), 4-5.
} 
A modo de conclusión se podrían plantear dos períodos históricos en América latina. Uno que abarca grosso modo el primer tercio del siglo XIX en el que todavía no hay masonería pero se habla y debate mucho de ella y sobre ella. Y una segunda mitad de siglo en la que la masonería y los masones son en muchos casos protagonistas conocidos o no de esa historia.

En los dos casos, aunque en el primero sea por atribución más gratuita que real, la masonería, sobre todo en ciertos autores que se ocupan de este asunto, va a quedar identificada en Iberoamérica con los libertadores y la independencia y con una forma de hacer política al ser portadora y difusora de principios y valores como el liberalismo, la república, la federación ${ }^{28}$, la soberanía, la igualdad, los derechos individuales... y la secularización del espacio público.

Sin embargo para la mayoría de los historiadores la masonería o es ignorada o no pasa de ser un hecho marginal o anecdótico más propio de las ciencias ocultas que de las sociales ${ }^{29}$.

Finalmente para nosotros el triángulo formado por REHMLAC, CEHME y SPIHM ${ }^{30}$ en cuanto red internacional de estudios históricos de las masonerías, constituye un equipo de trabajo y un objeto histórico de estudio e investigación multicultural y multinacional que tiene como centro la masonería vista desde un amplio abanico multidisciplinar en el que no está ausente ningún aspecto histórico, social, político y cultural. Equipo que investiga y publica de forma coordinada en América y Europa, especialmente desde REHMLAC-que hoy nos reúne aquí- pero también desde la colección Historia de la Masonería (editada por masonica.es) que con tanto acierto dirige nuestro organizador Yván Pozuelo, y de los que pronto serán ya 30 volúmenes de actas de los catorce simposios internacionales de historia de la masonería española, celebrados en España, Gibraltar y Portugal entre 1983 y 2018, y organizados por el CEHME estos últimos 35 años. De esta forma estamos contribuyendo a ofrecer una amplia y variada bibliografía que tal vez algún día ayude a romper los estereotipos, tópicos y falsedades que todavía hoy rodean a esta pequeña parcela de la historia que no es tan mala como algunos creen, ni tan buena como otros desean.

\section{Bibliografía}

Avendaño, Rómulo. Revista de Buenos Aires, t. 19 (1869): 439.

Arango Jaramillo, Mario. Masonería y partido liberal. Otra cara en la historia de Colombia. Medellín: Corselva, 2006.

Arango Jaramillo, Mario. Masonería y poder político en Colombia. Medellín: Hombre Nuevo Ed., 2011.

Ballester Escalas, R. Simón Bolivvar. Barcelona: Ed. Toray, 1963.

Bastian, Jean-Pierre. "Una ausencia notoria: la francmasonería en la historiografía mexicanista", Historia Mexicana, no. 3 (1995), 439-460.

\footnotetext{
${ }^{28} \mathrm{Al}$ igual que en los Estados Unidos de Norteamérica, otros países de América también adoptaron la forma de república federal, como Brasil y México.

${ }^{29}$ En este sentido resulta muy esclarecedor el lugar destinado a la masonería en la mayor parte de las librerías y editoriales e incluso en no pocas bibliotecas.

${ }^{30}$ REHMLAC (Revista de Estudios Históricos de la Masonería Latinoamericana y Caribeña), CEHME (Centro de Estudios Históricos de la Masonería Española) y SPIHM (Seminario Permanente Internacional de Historia de las Masonerías).
} 
Carnicelli, Américo. La masonería en la independencia de América. Bogotá: 1970.

Carnicelli, Américo. Historia de la masonería colombiana, 1833-1940. Bogotá: 1975.

Documentos Relativos a las últimas ocurrencias de Nueva España. Madrid: Ibarra, 1821.

Ercilla y Zúñiga, Alonso de. La Araucana. Madrid: Gaspar y Roig Ed. 1852.

Ferrer Benimeli, José Antonio. Masonería española contemporánea. Madrid: Siglo XXI de España Ed., 1980.

Ferrer Benimeli, José Antonio. "Bolívar y la masonería”. Revista de Indias 172 (julio-diciembre 1983): 631-687.

Ferrer Benimeli, José Antonio. "Vías de penetración de la masonería en el Caribe". REHMLAC $\begin{array}{lllll}1, & \text { no. } & 1 & \text { 2009): }\end{array}$ https://revistas.ucr.ac.cr/index.php/rehmlac/article/view/6853

Ferrer Benimeli, José Antonio. "Las logias Lautaro, los caballeros racionales y el movimiento independentista americano". En Masonería y sociedades secretas en México. Coordinado por José Luis Soberanes Fernández y Carlos Francisco Martínez Moreno. México: UNAM, 2018.

Flores Zavala, Marco Antonio. "Masonería y masones en México, 1760-1936”. Tesis doctoral, Universitat Jaume I, 2016.

González-Bernaldo de Quirós, Pilar. Civilité et politique aux origines de la nation argentine. Les sociabilités à Buenos Aires, 1829-1862. París: Publications de la Sorbonne, 1999.

Guerra, François-Xavier. Le Mexique, de l'Ancien régime à la Révolution, (Paris, Publications de la Sorbonne, 1985.

Guzmán-Stein, Miguel. “Liberalismo, Educación, Iglesia y Masonería: el proceso de formación y secularización del estado nacional a través de las relaciones institucionales en Costa Rica en el siglo XIX”. Tesis doctoral, universidad de Zaragoza, 2005.

Hoenigsberg, Julio. Influencia revolucionaria de la masonería en Europa y América. Bogotá: 1944.

Lacroix, Luis Perú de. Diario de Bucaramanga. Caracas: Edición de Monseñor Nicolás E. Navarro, 1935.

Loaiza Cano, Gilberto. Manuel Ancízar y su época. Medellín: Universidad Nacional de Colombia, 2004.

Loaiza Cano, Gilberto. "La masonería y las facciones del liberalismo colombiano durante el siglo XIX. El caso de la masonería de la Costa Atlántica”. Historia y Sociedad 13 (2007): 65-89, http://bdigital.unal.edu.co/23504/1/20438-68977-1-PB.pdf

Maguirre, José Patricio. "Algunos antecedentes para evaluar la influencia de la masonería en la liberación de Hispanoamérica". Boletín del Instituto de Historia Argentina, no. 16-11 (1968-1969).

Martínez Esquivel, Ricardo. Masones y masonería en la Costa Rica de los albores de la Modernidad (1865-1899). San José: Editorial de la Universidad de Costa Rica, 2017.

Martínez Moreno, Carlos Francisco. "El establecimiento de las masonerías en México en el siglo XIX”. Tesis de Maestría, UNAM, 2011.

Martínez Zaldúa: Ramón. La masonería en Hispanoamérica (Su influencia decisiva en la revolución mexicana). México: B. Costa-Amie, 1965.

Morales Padrón, Francisco. Historia de América. Madrid: Espasa Calpe, 1962. 
Navarro, Nicolás E. La masonería y la independencia. Caracas: Ed. Sur-Americana, 1928.

Navarro, Nicolás Eugenio. Tópicos bolivarianos. Glosas al "Diario de Bucaramanga". Caracas: 1933): 17-20.

Reyes Heredia, Guillermo de los. Herencias secretas. Masonería, política y sociedad en México. El impacto de la masonería en el discurso nacionalista, secular y liberal en México. Puebla: Universidad Autónoma, 2009.

Santos Molano, Enrique. Antonio Nariño, filósofo y revolucionario. Bogotá: Planeta, 1999.

Sardá y Salvany, Félix. Masonismo y Catolicismo. Paralelos entre la doctrina de las logias y la de nuestra santa Iglesia católica apostólica y romana. Barcelona: Librería Católica, 1885.

Sardá y Salvany, Félix. El liberalismo es pecado. Barcelona: Librería Católica, 1887.

Skinner Vásquez, Marco Aurelio. Influencia de la masonería en la revolución independentista de la Gran Colombia. ¿Verdad o mito? Bucaramanga: 2013.

Solar, Felipe Santiago del. Las logias de ultramar. En torno a los orígenes de la francmasonería en Chile 1850-1862. Santiago de Chile: Occidente, 2012.

Torres Cuevas, Eduardo. Historia de la masonería cubana. Seis ensayos. La Habana: Imagen Contemporánea, 2004.

Vázquez Semadeni, María Eugenia. La formación de una cultura política republicana. El debate público sobre la masonería. México, 1821-1830. México: UNAM, 2010.

Wilson, Carlos. "125 años de Masonería”. La palabra de la Masonería 1 (diciembre 1982): 58. 